\title{
DESENVOLVIMENTO VEGETATIVO DE PLANTAS E QUALIDADE FISIOLÓGICA DE SEMENTES DE ARROZ PRODUZIDAS EM ÁREAS DE RECUPERAÇÃO DE PASTAGEM ${ }^{1}$
}

\author{
MARCO ANTONIO CAMILLO DE CARVALHO ${ }^{2}$, OSCAR MITSUO YAMASHITA², \\ RAFAEL NOETZOLD ${ }^{3}$, DELMONTE ROBOREDO ${ }^{2}$
}

\begin{abstract}
RESUMO - O presente trabalho teve como objetivo avaliar o desenvolvimento vegetativo e a qualidade fisiológica de sementes de cultivares de arroz produzidas em sistemas alternativos para a renovação de pastagem. O trabalho foi conduzido no município de Alta Floresta-MT, na safra 2006/07. O delineamento experimental utilizado foi o de blocos casualizados em esquema fatorial 2x8, perfazendo 16 tratamentos, constituídos pela combinação 2 cultivares de arroz (Oryza sativa L.) (BRS Primavera e BEST 2000) e 8 modos de redução no desenvolvimento da braquiária (Brachiaria brizantha cv. Marandu), sendo 4 doses reduzidas do herbicida cyhalofop butil $\left(180 \mathrm{~g} \mathrm{~L}^{-1}\right)(0 ; 0,40$; 0,80 e 1,2 $\mathrm{L} \mathrm{ha}^{-1}$ ) e a semeadura da braquiária a lanço e com incorporação aos 10 e 20 dias após a emergência do arroz. Todos os tratamentos tiveram 4 repetições. Nos tratamentos em que a braquiária recebeu doses reduzidas de herbicida, a forrageira foi semeada juntamente com o arroz. Foram avaliadas as seguintes características vegetativas: altura de planta, comprimento e diâmetro de entre nó e índice de área foliar e os seguintes testes de qualidade fisiológica de sementes: germinação, primeira contagem, índice de velocidade de germinação, condutividade elétrica e envelhecimento acelerado. O cultivar BRS Primavera produziu sementes de melhor qualidade; todas as alternativas estudadas mostram-se viáveis para a produção de sementes e a região de Alta Floresta mostra-se apta para a produção de sementes de arroz.
\end{abstract}

Termos para indexação: Oryza sativa L., integração lavoura pecuária, cyhalofop butil

\section{ASSESS THE GROWTH AND PHYSIOLOGICAL QUALITY OF SEEDS OF RICE CULTIVARS GROWN IN ALTERNATIVES TO THE RENEWAL OF PASTURE}

\begin{abstract}
The objective of this study was to assess the growth and physiological quality of seeds of rice cultivars grown in alternative systems for pasture renewal. The study was conducted in the municipality of Alta Floresta-MT in the 2006/07growing season. The experimental design was in randomized blocks with 4 replications in a $2 \times 8$ factorial scheme, consisting of the combination of two rice cultivars (BRS Primavera and BEST 2000) and eight options for renewal, and four low concentrations of the cyhalofop butil herbicide $\left(180 \mathrm{~g} \mathrm{~L}^{-1}\right)\left(0,0.40,0.80\right.$ and $\left.1.2 \mathrm{~L} \mathrm{ha}^{-1}\right)$ and brachiaria
\end{abstract} ${ }^{1}$ Submetido em 15/02/2009. Aceito para publicação em 16/09/2009.
Trabalho financiado pela Fundação de Amparo a Pesquisa do Estado de
Mato Grosso- FAPEMAT.

${ }^{2}$ Eng. Agr., Professor Departamento de Agronomia, Universidade do Estado de Mato Grosso - UNEMAT, Campus Alta Floresta, Rodovia MT 208, km 145, Caixa Postal 324, CEP:78580-000, Alta Floresta-MT. marco@w3nt. com; yama@unemat.br; roboredo@gmail.com.

${ }^{3}$ Eng. Agr., Universidade do Estado de Mato Grosso - UNEMAT, Campus Alta Floresta, Rodovia MT 208, km 145, Caixa Postal 324, CEP:78580000, Alta Floresta-MT. gaucho@w3nt.com. 
sown by hand and incorporated 10 and 20 days after rice emergence. In treatments in which brachiaria received low herbicide concentrations, the grass was sown together with the rice. The following plant characteristics were evaluated: plant height, length and diameter of between node and leaf area index. The tests on physiological quality of seed, germination, first count, speed of germination index, electrical conductivity and accelerated aging were carried out. The BRS Primavera cultivar produced seed of better quality, all the alternatives were shown to be viable for seed and the region of Alta Floresta was shown to be suitable for rice seed production.

Index terms: Oryza sativa L., crop-pasture integration, cyhalofop butyl

\section{INTRODUÇÃO}

A junção das palavras Amazônia, meio ambiente, desenvolvimento econômico e desmatamento originam o polêmico tema anexado à pauta da opinião pública mundial. O tema é composto por uma complexa malha de ações antrópicas, que responsabiliza a atividade da pecuária extensiva como um dos principais agentes supressores da floresta. Dentro dessa perspectiva, existe a necessidade de buscar alternativas que promovam o desenvolvimento regional, mas sem perder de vista as considerações sobre a sustentabilidade, de forma que o solo seja considerado um recurso natural renovável (Ichihara, 2003).

Devido ao manejo inadequado das pastagens e ao uso indiscriminado desses solos, está ocorrendo uma diminuição dos teores de matéria orgânica, além disso, o pisoteio dos animais contribui para a degradação das pastagens. Segundo Costa et al. (2006) na região Amazônica do Brasil, cerca de $40 \%$ das pastagens cultivadas se encontram em estágios avançados de degradação, os quais se manifestam pela baixa disponibilidade de foragem, dominância de plantas invasoras, baixa cobertura e erosão do solo.

Nos últimos anos, muitas informações foram geradas pela pesquisa, dando origem a várias tecnologias de recuperação/renovação de pastagens (Zimmer et al., 1994). A forrageira, no sistema consorciado, pode ser semeada simultaneamente com a cultura produtora de grãos. Outra forma de implantação desse sistema é a semeadura da forrageira no momento da aplicação do fertilizante de cobertura, ambos misturados, podendo ser utilizados até com formulados (Borghi e Crusciol, 2007).

Para o sucesso da integração lavoura pecuária, é necessário que a cultura a ser consorciada com a forrageira apresente na região, a cadeia produtiva consolidada. A cadeia produtiva de arroz do Mato Grosso, nos últimos anos, tem sido de grande importância para o desenvolvimento da região norte do Estado. Graças à abertura de novos mercados para o arroz de terras altas, a cultura tende a ser mais rentável e, ao mesmo tempo, mais exigente em seu manejo técnico (Souza et al., 2007).

$\mathrm{Na}$ recuperação de pastagem, através da integração lavoura pecuária, pode-se utilizar como estratégia para o aumento da receita, a produção de sementes da cultura, para posterior utilização na propriedade ou comercialização. A semente, do ponto de vista agronômico, é o insumo que dá origem a um novo cultivo e da qual, em função de suas características e da maneira como é utilizada, dependem os resultados da nova safra (Menon et al., 1993).

Segundo Souza et al. (2007), as sementes de arroz utilizadas no norte do Mato Grosso apresentam qualidade abaixo da exigida pela legislação, constituindo-se em um importante fator restritivo à obtenção de lavouras produtivas e posteriormente de um produto de qualidade.

Pesquisas que visem avaliar a qualidade fisiológica das sementes produzidas em determinada região são de grande importância, pois indicam a possibilidade dessa região ser ou não apta à produção de sementes. Krzyzanowski e França Neto (1991) relatam a importância da determinação do vigor de sementes, na medida em que os métodos de avaliação vêm sendo aperfeiçoados.

Considerando que o município de Alta Floresta apresenta uma área territorial de aproximadamente $895 \mathrm{mil}$ hectares e destes, aproximadamente 367 mil correspondem à área desmatada, e $80 \%$ desta área está sendo utilizada com pastagem com variados graus de degradação, fazse necessário o desenvolvimento de estudos que visem à reabilitação destas áreas e que as mesmas voltem a ser produtivas. O presente trabalho teve como objetivo avaliar o desenvolvimento vegetativo e a qualidade fisiológica de sementes de cultivares de arroz produzidas em sistemas 
alternativos para a renovação de pastagem.

\section{MATERIAL E MÉTODOS}

O experimento foi instalado em campo, no ano agrícola de 2006/07, na área experimental da Universidade do Estado de Mato Grosso, no município de Alta FlorestaMT, em solo originalmente sob vegetação amazônica. A área apresenta como coordenadas geográficas: 0952'32" latitude Sul e $56^{\circ} 09^{\prime} 10^{\prime \prime}$ latitude Oeste e com altitude de 290 metros. A precipitação média anual é de $2.750 \mathrm{~mm}$ e a temperatura média anual é de $24^{\circ} \mathrm{C}$. O solo do local é da classe Latossolo Vermelho-Amarelo distrófico típico argiloso (Embrapa, 1999). As características químicas do solo, no perfil de 0-0,20 m, são: $\mathrm{pH}\left(\mathrm{H}_{2} \mathrm{O}\right)$ de 5,4, P e K de 1,2 e $104 \mathrm{mg} \mathrm{dm}^{-3}$ e teores de $\mathrm{Ca}, \mathrm{Mg}$, $\mathrm{Al}$ e $\mathrm{H}$ de 1,63; 0,$56 ; 0,25 ; 3,38 \mathrm{cmol}_{c} \mathrm{dm}^{-3}$, respectivamente e M.O. de 13 $\mathrm{g} \mathrm{dm}^{-3}$.

O preparo de solo foi realizado através de duas gradagens pesadas e duas leves, sendo que a calagem foi realizada com a aplicação de $1.000 \mathrm{~kg} \mathrm{ha}^{-1}$ de calcário dolomítico 3 meses antes da implantação do experimento. O delineamento experimental utilizado foi o de blocos casualizados, em esquema fatorial $2 \times 8$, perfazendo 16 tratamentos, constituídos pela combinação 2 cultivares de arroz (Oryza sativa L.) (BRS Primavera e BEST 2000) e 8 modos de redução no desenvolvimento da braquiária (Brachiaria brizantha cv. Marandu), sendo 4 doses reduzidas do herbicida cyhalofop butil $\left(180 \mathrm{~g} \mathrm{~L}^{-1}\right)(0 ; 0,40$; 0,80 e $\left.1,2 \mathrm{~L} \mathrm{ha}^{-1}\right)$ e a semeadura da braquiária a lanço e com incorporação aos 10 e 20 dias após a emergência do arroz. Nos tratamentos em que a braquiária recebeu doses reduzidas de herbicida, a forrageira foi semeada juntamente com o arroz.

As parcelas foram constituídas por 7 linhas de 5,0 m de comprimento espaçadas $0,30 \mathrm{~m}$ entre si. A área útil foi constituída pelas 5 linhas centrais, desprezando-se 0,50 $\mathrm{m}$ em ambas as extremidades de cada linha. Todos os tratamentos tiveram 4 repetições.

A adubação básica foi calculada de acordo com as recomendações de Paula et al. (1999), sendo aplicado na semeadura $20 \mathrm{~kg} \mathrm{ha}^{-1}$ de $\mathrm{N}, 150 \mathrm{~kg} \mathrm{ha}^{-1}$ de $\mathrm{P}_{2} \mathrm{O}_{5}$ e $50 \mathrm{~kg}$ $\mathrm{ha}^{-1}$ de $\mathrm{K}_{2} \mathrm{O}$, utilizando-se como fontes, uréia, super fosfato simples e cloreto de potássio, respectivamente. A semeadura foi realizada em 12/11/2006, utilizando-se $70 \mathrm{~kg} \mathrm{ha}^{-1}$.

O cultivar BRS-Primavera teve a sua colheita realizada em 19/02/2007 e o cultivar BEST 2000 em 12/03/2007.

Nos tratamentos que receberam as doses reduzidas do herbicida cyhalofop butil, a aplicação foi realizada quando a braquiária apresentava 3 a 4 perfilhos, estando o arroz com 30 dias de emergência. A aplicação foi realizada com auxílio de pulverizador costal, pressurizado por gás carbônico $\left(\mathrm{CO}_{2}\right)$, operando com pressão constante de $250 \mathrm{kPa}$, acoplado a uma barra contendo 4 pontas de pulverização do tipo "leque" (SF 110.02), distanciadas de $0,5 \mathrm{~m}$, proporcionando a aplicação de volume de calda de $200 \mathrm{~L} \mathrm{ha}^{-1}$.

Na cultura do arroz, foram avaliados: altura de plantas, comprimento de entre nós, diâmetro de colmo e índice de área foliar, durante o florescimento pleno.

A qualidade fisiológica das sementes foi avaliada pelos seguintes testes: Germinação - conduzido em germinador tipo BOD $\left(25^{\circ} \mathrm{C}\right)$, com quatro repetições de 50 sementes para cada parcela de campo. As sementes foram distribuídas em rolo de papel toalha umedecido com água destilada, na proporção de 2,5 vezes o seu peso seco. As contagens de plântulas normais foram realizadas aos 5 e 10 dias após a instalação do teste (Brasil, 1992), sendo os resultados expressos em porcentagem; Primeira Contagem do Teste de Germinação - porcentagem de plântulas normais computadas por ocasião da primeira contagem do teste de germinação; Índice de Velocidade de Germinação (IVG) - Determinado em conjunto com o teste de germinação, avaliando-se diariamente a porcentagem de plântulas normais até os 10 dias após a semeadura. O IVG foi determinado empregando-se a fórmula apresentada por Maguire (1962); Envelhecimento Acelerado - Conduzido em caixas plásticas tipo "gerbox" modificada, contendo 40 $\mathrm{mL}$ de água destilada, com quatro repetições de 50 sementes, uma de cada parcela. Essas caixas foram mantidas a $42{ }^{\circ} \mathrm{C}$ por um período de 72 horas (Vieira e Carvalho, 1994). Em seguida, as sementes foram submetidas ao teste de germinação, conforme descrição anterior, com contagens das plântulas normais aos 5 dias após a semeadura, sendo os resultados expressos em porcentagem; Condutividade Elétrica - foi determinada com quatro repetições de 50 sementes, uma de cada parcela de campo, pesadas e dispostas em recipientes plásticos $(200 \mathrm{~mL})$ contendo 75 $\mathrm{mL}$ de água destilada. Após 24 horas em câmara tipo BOD a $25{ }^{\circ} \mathrm{C}$, foi efetuada a leitura da condutividade elétrica utilizando um condutivímetro modelo Digimed D30. Os resultados de condutividade foram expressos em $\mu \mathrm{S} . \mathrm{cm}^{-1}$. $\mathrm{g}^{-1}$ de semente.

Os dados obtidos foram submetidos à análise de variância utilizando o programa SANEST (Zonta e Machado, 1984). As médias dos tratamentos foram comparadas pelo teste de Tukey a 5\% de probabilidade, de acordo com Pimentel- 
Gomes (1987).

\section{RESULTADOS E DISCUSSÃO}

O resumo da análise de variância e os valores médios das características referentes ao desenvolvimento vegetativo encontram-se apresentadas na Tabela 1. Para todas as características vegetativas, ocorreu diferença entre os cultivares. Não houve diferença entre as alternativas, não havendo também interação significativa entre os fatores para as variáveis estudadas.

TABELA 1. Valores de F, Coeficiente de Variação (C.V.) e Diferença Mínima Significativa (DMS) para Altura de plantas, Comprimento de entre nó, Diâmetro de entre nó, Índice de Área Foliar, de cultivares de arroz submetidos a diferentes alternativas de recuperação de pastagem.

\begin{tabular}{|c|c|c|c|c|}
\hline & Altura de plantas $(\mathrm{cm})$ & $\begin{array}{c}\text { Comprimento de entre } \\
\text { nó }(\mathrm{cm})\end{array}$ & $\begin{array}{l}\text { Diâmetro de entre nó } \\
(\mathrm{mm})\end{array}$ & $\begin{array}{l}\text { Índice de Área Foliar } \\
\qquad\left(\mathrm{m}^{2} \mathrm{~m}^{-2}\right)\end{array}$ \\
\hline \multicolumn{5}{|l|}{ Cultivares } \\
\hline Primavera & $111 \mathrm{a}$ & $21,9 \mathrm{a}$ & $0,35 \mathrm{~b}$ & $2,29 \mathrm{~b}$ \\
\hline BEST 2000 & $84 \mathrm{~b}$ & $13,3 \mathrm{~b}$ & $0,49 \mathrm{a}$ & $3,33 \mathrm{a}$ \\
\hline Valor de F & $219,6^{*}$ & $287,5^{* *}$ & $139,4 * *$ & $31,27 * *$ \\
\hline DMS (5\%) & 3,0 & 1,02 & 0,02 & 0,37 \\
\hline \multicolumn{5}{|l|}{ Alternativas } \\
\hline 1 & 97 & 16,9 & 0,40 & 2,68 \\
\hline 2 & 99 & 17,5 & 0,41 & 2,84 \\
\hline 3 & 95 & 16,9 & 0,44 & 2,60 \\
\hline 4 & 96 & 17,4 & 0,41 & 3,00 \\
\hline 5 & 95 & 16,7 & 0,38 & 2,58 \\
\hline 6 & 101 & 18,8 & 0,42 & 2,89 \\
\hline 7 & 99 & 17,7 & 0,42 & 2,85 \\
\hline 8 & 101 & 18,8 & 0,41 & 3,04 \\
\hline Valor de F & $0,99 \mathrm{~ns}$ & $1,30 \mathrm{~ns}$ & $0,76 \mathrm{~ns}$ & $0,42 \mathrm{~ns}$ \\
\hline DMS (5\%) & 24,12 & 3,23 & 0,08 & 1,18 \\
\hline $\begin{array}{l}\text { Valor de F } \\
\text { (Interação) }\end{array}$ & $2,06 \mathrm{~ns}$ & $2,08 \mathrm{~ns}$ & $0,93 \mathrm{~ns}$ & $0,69 \mathrm{~ns}$ \\
\hline C.V. $\%$ & 7,33 & 11,58 & 12,67 & 26,55 \\
\hline
\end{tabular}

Alternativas: 1-Dose 0; 2-Dose 0,40; 3-Dose 0,80, 4-Dose 1,2 $\mathrm{L} \mathrm{ha}^{-1}$ do herbicida cyhalofop butil, 5-Semeadura de braquiária a lanço aos 10 dias após a emergência do arroz e 6-Semeadura de braquiária a lanço aos 20 dias após a emergência do arroz, 7- Semeadura de braquiária no sulco aos 20 dias após a emergência do arroz, 8- Semeadura de braquiária no sulco aos 30 dias após a emergência do arroz.

Valores seguidos pelas mesmas letras não diferem entre si a 5\% de probabilidade pelo teste de Tukey.

O cultivar BRS Primavera apresentou maior altura de plantas e de comprimento de entre nó (Tabela 1). Essa diferença está ligada às características genéticas dos cultivares. Em pesquisa realizada no Estado de Roraima por Medeiros (2000), o cultivar BRS Primavera apresentou altura variando de 100 a $120 \mathrm{~cm}$, concordando com o observado na presente pesquisa. Segundo este mesmo autor, o cultivar BRS Primavera é tido como rústico, sendo muito utilizado em áreas de abertura e em área já trabalhada sob condições de mata, com baixa ou média 
fertilidade. Quando cultivado em solos férteis, devem-se utilizar baixas doses de fertilizantes, principalmente os nitrogenados devido a sua sensibilidade ao acamamento. O cultivar BEST 2000 é considerado de arquitetura moderna (folhas eretas, porte baixo, grande capacidade de perfilhamento) e exige nível tecnológico alto (Agronorte, 2009).

Para o diâmetro de entre nó e índice de área foliar (IAF), o BEST 2000 foi superior. Isto novamente reflete a diferença genética entre os materiais e mostra que a sensibilidade do cultivar BRS Primavera ao acamamento pode estar ligada ao seu diâmetro de colmo. Em geral, plantas altas são mais propensas ao acamamento, que também depende do diâmetro e resistência do colmo, intensidade dos ventos e disponibilidade de água (Fonseca et al., 2002). Yoshida (1981) relata que, devido ao fato de o índice de área foliar ser uma propriedade muito variável, é difícil definir um valor ótimo. Em diferentes localidades e épocas, Pinheiro e Guimarães (1990), para o cultivar IAC 47 , relatam ampla variação de $\operatorname{IAF}\left(1,5\right.$ a $\left.8,3 \mathrm{~m}^{2} \cdot \mathrm{m}^{-2}\right)$, sendo que o máximo rendimento em grãos ocorreu com o IAF entre 4,5 a $6,3 \mathrm{~m}^{2} \cdot \mathrm{m}^{-2}$ e valores muito baixos do IAF (inferiores a 2,0), apesar de minimizarem o risco de perda por deficiência hídrica, restringem o potencial produtivo. Os valores observados na pesquisa encontram-se dentro da faixa considerada adequada, porém não ótima.

Ocorreram diferenças entre os cultivares para os testes germinação, envelhecimento acelerado e condutividade elétrica (Tabela 2). O cultivar BRS Primavera apresentou melhor qualidade fisiológica de sementes produzidas. Apesar da diferença existente entre as cultivares, notase que ambos apresentam ótimo potencial germinativo, uma vez que os mesmos apresentam germinação acima do padrão mínimo exigido para comercialização no Estado de Mato Grosso, o qual segue a recomendação do Ministério da Agricultura, Pecuária e Abastecimento, que tem como padrão para produção e comercialização de sementes de arroz a Instrução Normativa $\mathrm{n}^{\circ} 25$ de 16 de dezembro de 2005, que determina germinação mínima de $80 \%$.

A qualidade fisiológica e física das sementes de arroz depende do cultivar, estágio de maturação, conteúdo de umidade e danos mecânicos, que podem ocorrer durante a colheita, secagem, beneficiamento e mesmo no período de armazenamento (Smiderle e Dias, 2008).

Com relação às alternativas de recuperação de pastagem (Tabela 2), não ocorreu diferença significativa entre as mesmas somente no teste de primeira contagem. A alternativa com maior percentual germinativo e velocidade de germinação foi o tratamento 3 que recebeu aplicação de $0,80 \mathrm{~L} \mathrm{ha}^{-1}$ de cyhalofop butil. No entanto, ele foi superior no teste de germinação ao tratamento 6 (semeadura a lanço da forrageira após 20 dias da emergência da cultura) e no envelhecimento acelerado ao tratamento 4 (1,2 $\mathrm{L} \mathrm{ha}^{-1}$ do herbicida cyhalofop butil). Já para o índice de velocidade de germinação ele foi superior aos tratamentos 5 (semeadura a lanço da forrageira aos 10 dias após a emergência da cultura) e 6 (semeadura a lanço da forrageira aos 20 dias após a emergência da cultura) e, para a condutividade elétrica superior a todos os demais tratamentos.

O desdobramento da interação entre cultivar e alternativa para o teste de condutividade elétrica, encontrase apresentado na Tabela 3. Dentro do cultivar BRS Primavera, não ocorreu diferença entre as alternativas. No cultivar BEST 2000, o tratamento 3 (dose de 0,80 L ha ${ }^{-1}$ de cyhalofop butil) foi a que proporcionou pior qualidade, não diferindo do tratamento 6 (semeadura a lanço da forrageira após 20 dias da emergência da cultura). Dentro das alternativas de renovação, o cultivar BEST 2000 sempre apresentou pior qualidade, não diferindo do BRS Primavera apenas nas alternativas com a não aplicação do herbicida (tratamento 1) e nas alternativas com semeaduras no sulco aos 20 e 30 dias após emergência da cultura (tratamentos 7 e 8). O teste de condutividade elétrica, baseado na integridade dos sistemas de membranas, é de grande interesse na determinação do vigor das sementes, em virtude de permitir que o processo de deterioração seja detectado em sua fase inicial, possibilitando que os efeitos na qualidade fisiológica das sementes sejam reduzidos ou minimizados (Dias e Marcos Filho, 1995). A metodologia do teste baseia-se no conceito de que, quando as sementes são imersas em água, as de baixo vigor liberam quantidade de eletrólitos na solução, refletindo a perda de integridade das membranas celulares e consequentemente a perda de vigor.

Na Tabela 4 encontra-se apresentado o desdobramento da interação entre cultivares e alternativas de renovação para o teste de envelhecimento acelerado. No cultivar BRS Primavera não ocorreu diferença entre as alternativas. $\mathrm{Na}$ avaliação das alternativas dentro do cultivar BEST 2000, verifica-se que o tratamento 4 (dose maior do herbicida $\left.\left(1,2 \mathrm{~L} \mathrm{ha}^{-1}\right)\right)$ que não diferiu do tratamento 1 (não aplicação de herbicida) foram os que proporcionaram os piores resultados. Dentro das alternativas, somente ocorreu diferença entre os cultivares no tratamento 4 (dose maior de herbicida $\left(1,2 \mathrm{~L} \mathrm{ha}^{-1}\right)$ ), onde o cultivar 
BRS Primavera apresentou melhor média. O teste de envelhecimento acelerado consiste em avaliar a resposta das sementes por meio de teste de germinação, após elas terem sido submetidas à temperatura elevada e umidade relativa do ar próxima a $100 \%$, por determinado período de exposição (Marcos Filho, 2005). Nessas condições de estresse, sementes de menor qualidade deterioram-se mais rapidamente do que as mais vigorosas, com reflexos na germinação após o período de envelhecimento acelerado (Torres e Marcos Filho, 2001).

TABELA 2. Valores de F, Coeficiente de Variação (C.V.) e Diferença Mínima Significativa (DMS) para os testes de Condutividade Elétrica, Primeira Contagem, Índice e Velocidade de Germinação, Germinação e Envelhecimento Acelerado, de cultivares de arroz submetidos a diferentes alternativas de recuperação de pastagem.

\begin{tabular}{|c|c|c|c|c|c|}
\hline & $\begin{array}{l}\text { Condutividade } \\
\text { Elétrica } \\
\left(\mu \mathrm{S} \mathrm{cm}^{-1} \mathrm{~g}^{-1}\right)\end{array}$ & $\begin{array}{c}\text { Primeira } \\
\text { Contagem }(\%)\end{array}$ & IVG & $\begin{array}{c}\text { Germinação } \\
(\%)\end{array}$ & $\begin{array}{l}\text { Envelhecimento } \\
\text { Acelerado (\%) }\end{array}$ \\
\hline \multicolumn{6}{|l|}{ Cultivares } \\
\hline Primavera & $39,73 \mathrm{~b}$ & 23,56 & 7,23 & $93 \mathrm{a}$ & 86,18 a \\
\hline BEST 2000 & $49,67 \mathrm{a}$ & 23,75 & 7,03 & $90 \mathrm{~b}$ & $77,12 \mathrm{~b}$ \\
\hline Valor de F & $97,7 * *$ & $0,00 \mathrm{~ns}$ & $1,90 \mathrm{~ns}$ & $2,48^{*}$ & $23,41 * *$ \\
\hline DMS (5\%) & 2,77 & 7,42 & 0,28 & 2,80 & 3,77 \\
\hline \multicolumn{6}{|l|}{ Alternativas* } \\
\hline 1 & $41,45 \mathrm{~b}$ & 30,00 & $7,25 \mathrm{ab}$ & $90 \mathrm{ab}$ & $77,00 \mathrm{ab}$ \\
\hline 2 & $46,04 \mathrm{~b}$ & 34,00 & $7,19 \mathrm{ab}$ & $95 \mathrm{a}$ & $79,25 \mathrm{ab}$ \\
\hline 3 & 52,93 a & 16,50 & $7,66 \mathrm{a}$ & $95 \mathrm{a}$ & $86,75 \mathrm{a}$ \\
\hline 4 & $45,33 \mathrm{~b}$ & 21,75 & $7,22 \mathrm{ab}$ & $94 \mathrm{ab}$ & $71,75 \mathrm{~b}$ \\
\hline 5 & $43,59 \mathrm{~b}$ & 16,50 & $6,71 \mathrm{~b}$ & $89 a b$ & $81,25 \mathrm{ab}$ \\
\hline 6 & $44,99 \mathrm{~b}$ & 18,75 & $6,57 \mathrm{~b}$ & $86 \mathrm{~b}$ & $87,50 \mathrm{a}$ \\
\hline 7 & $43,70 \mathrm{~b}$ & 22,25 & $7,14 \mathrm{ab}$ & $91 \mathrm{ab}$ & $87,50 \mathrm{a}$ \\
\hline 8 & $40,30 \mathrm{~b}$ & 29,50 & $7,31 \mathrm{ab}$ & $92 \mathrm{ab}$ & $82,25 \mathrm{ab}$ \\
\hline Valor de F & $7,14^{*}$ & $1,65 \mathrm{~ns}$ & $2,93^{*}$ & $7,03^{*}$ & $4,49 *$ \\
\hline DMS (5 \%) & 6,49 & 23,45 & 0,90 & 8,83 & 11,90 \\
\hline $\begin{array}{l}\text { Valor de F } \\
\text { (Interação) }\end{array}$ & $8,59 * *$ & $1,69 \mathrm{~ns}$ & $2,16 \mathrm{~ns}$ & $1,71 \mathrm{~ns}$ & $5,63 * *$ \\
\hline C.V. \% & 9,13 & 62,34 & 7,97 & 6,06 & 5,63 \\
\hline
\end{tabular}

* Alternativas: 1-Dose 0; 2-Dose 0,40; 3-Dose 0,80, 4-Dose 1,2 L ha-1 do herbicida cyhalofop butil, 5-Semeadura de braquiária a lanço aos 10 dias após a emergência do arroz e 6-Semeadura de braquiária a lanço aos 20 dias após a emergência do arroz, 7- Semeadura de braquiária no sulco aos 20 dias após a emergência do arroz, 8- Semeadura de braquiária no sulco aos 30 dias após a emergência do arroz.

Valores seguidos pelas mesmas letras não diferem entre si a 5\% de probabilidade pelo teste de Tukey.

ns não significativo pelo Teste F.

** significativo a $1 \%$ de probabilidade segundo o Teste $\mathrm{F}$.

* significativo a $5 \%$ de probabilidade segundo o Teste $\mathrm{F}$. 
TABELA 3. Comportamento Teste de Condutividade Elétrica $\left(\mu \mathrm{S} \mathrm{cm} \mathrm{cm}^{-1}\right)$ em função dos cultivares e alternativas de recuperação de pastagem.

\begin{tabular}{ccc}
\hline Alternativas* & \multicolumn{2}{c}{ Cultivares } \\
\cline { 2 - 3 } & BRS Primavera & BEST 2000 \\
\hline 1 & $57,25 \mathrm{a} \mathrm{A}$ & $54,67 \mathrm{c} \mathrm{A}$ \\
2 & $54,97 \mathrm{a} \mathrm{B}$ & $69,35 \mathrm{~b} \mathrm{~A}$ \\
3 & $58,15 \mathrm{a} \mathrm{B}$ & $84,77 \mathrm{a} \mathrm{A}$ \\
4 & $51,77 \mathrm{a} \mathrm{B}$ & $70,62 \mathrm{~b} \mathrm{~A}$ \\
5 & $48,22 \mathrm{a} \mathrm{B}$ & $69,45 \mathrm{~b} \mathrm{~A}$ \\
6 & $48,37 \mathrm{a} \mathrm{B}$ & $73,10 \mathrm{ab} \mathrm{A}$ \\
7 & $56,05 \mathrm{a} \mathrm{A}$ & $59,95 \mathrm{bc} \mathrm{A}$ \\
8 & $54,30 \mathrm{a} \mathrm{A}$ & $54,52 \mathrm{c} \mathrm{A}$ \\
\hline
\end{tabular}

* Alternativas: 1-Dose 0; 2-Dose 0,40; 3-Dose 0,80, 4-Dose 1,2 $\mathrm{L} \mathrm{ha}^{-1}$ do herbicida cyhalofop butil, 5-Semeadura de braquiária lanço a aos 10 dias após a emergência do arroz e 6-Semeadura de braquiária a lanço aos 20 dias após a emergência do arroz, 7- Semeadura de braquiária no sulco aos 20 dias após a emergência do arroz, 8- Semeadura de braquiária no sulco aos 30 dias após a emergência do arroz.

Médias seguidas de mesma letra, minúscula na coluna e maiúscula na linha, não diferem entre si pelo teste de Tukey a $5 \%$ de probabilidade.

TABELA 4. Comportamento do Teste de Envelhecimento Acelerado em função dos cultivares e alternativas de recuperação de pastagem.

\begin{tabular}{ccc}
\hline & \multicolumn{2}{c}{ Cultivares } \\
\cline { 2 - 3 } Alternativas* & BRS & BEST \\
& Primavera & 2000 \\
\hline 1 & 84,5 a A & $69,5 \mathrm{ab} \mathrm{A}$ \\
2 & 86,5 a A & 72,0 a A \\
3 & 90,0 a A & 83,5 a A \\
4 & 89,0 a A & 54,5 b B \\
5 & 78,5 a A & 84,0 a A \\
6 & 88,5 a A & 86,5 a A \\
7 & 86,5 a A & 88,5 a A \\
8 & 86,0 a A & 78,5 a A \\
\hline
\end{tabular}

Alternativas: 1-Dose 0; 2-Dose 0,40; 3-Dose 0,80, 4-Dose 1,2 $\mathrm{L} \mathrm{há}^{-1}$ do herbicida cyhalofop butil, 5-Semeadura de braquiária a lanço aos 10 dias após a emergência do arroz e 6-Semeadura de braquiária a lanço aos 20 dias após a emergência do arroz, 7- Semeadura de braquiária no sulco aos 20 dias após a emergência do arroz, 8- Semeadura de braquiária no sulco aos 30 dias após a emergência do arroz.

Médias seguidas de mesma letra, minúscula na coluna e maiúscula na linha, não diferem entre si pelo teste de Tukey a 5\% de probabilidade.

\section{CONCLUSÕES}

Todas as alternativas de renovação de pastagem estudadas são viáveis para a produção de sementes de arroz com alta qualidade fisiológica.

A região de Alta Floresta-MT mostra-se apta para a produção de sementes de arroz de terras altas.

As cultivares produzem sementes com qualidade acima do padrão mínimo para a comercialização, com superioridade da cultivar BRS Primavera.

\section{AGRADECIMENTOS}

Agradecimentos a Fundação de Amparo a Pesquisa do Estado de Mato Grosso - FAPEMAT, pelo apoio financeiro.

\section{REFERÊNCIAS}

AGRONORTE. Características da cultivar Best 2000. Disponível em: <http://www.agronorte.com.br/mostra. php?id=65>. Acesso em: 28 jan. 2009.

BORGHI, E.; CRUSCIOL, C.A.C. Produtividade de milho, espaçamento e modalidade de consorciação com Brachiaria brizantha em sistema de plantio direto. Pesquisa Agropecuária Brasileira, v.42, n.2, p.163-171, 2007.

BRASIL. Ministério da Agricultura e Reforma Agrária. Secretaria Nacional de Defesa Agropecuária. Departamento Nacional de Produção Vegetal. Coordenação de Laboratório Vegetal. Regras para Análise de Sementes. Brasília, DF, $1992.365 \mathrm{p}$.

COSTA, N.L.; TOWNSEND, C.R.; MAGALHÃES, J.A.; PAULINO, V.T.; ARAÚJO, R.G. Recuperação e renovação de pastagens degradadas. Revista Eletrônica de Veterinária REDVET, v.7, n.1, p.9-49, 2006.

DIAS, D.C.F.S.; MARCOS FILHO, J. Testes de vigor baseados na permeabilidade das membranas celulares: I Condutividade elétrica. Informativo ABRATES, v.5, n.1, p.26-41, 1995.

EMBRAPA Solos. Sistema brasileiro de classificação de solos. Rio de Janeiro: Embrapa Solos, 1999. 412p.

FONSECA, J.R.; CUTRIM, V.A.; RANGEL, P.H.N. Descritores morfo agronômicos e fenológicos de cultivares comerciais de arroz de várzea. Santo Antônio de Goiás: Embrapa Arroz e Feijão, 2002. 25p. (Embrapa Arroz e Feijão. Documentos, 141).

ICHIHARA, S. M. Desmatamento e recuperação de 
pastagens degradadas na região amazônica: uma abordagem através da análise de projetos. 2003. $124 \mathrm{f}$. Dissertação (Mestrado em Agronomia) - Universidade de São Paulo - Escola Superior de Agronomia Luiz de Queiroz, Piracicaba.

KRZYZANOWSKI, F.C.; FRANÇA-NETO, J.B. Teste de vigor em sementes. In: ENCONTRO SOBRE AVANÇOS EM TECNOLOGIA DE SEMENTES. Pelotas, 1991, Anais... Pelotas: UFPel- FAEM-DF, 1991. p.97-103.

MAGUIRE, J.D. Speed of germination-aid in relation evaluation for seedling emergence vigor. Crop Science, v.2, n.2, p.176-177, 1962.

MARCOS FILHO, J. Fisiologia de sementes de plantas cultivadas. Piracicaba: FEALQ, 2005. 495p.

MEDEIROS, R.D. Primavera e bonança: novas cutivares de arroz de sequeiro para o Estado de Roraima. Boa Vista: Embrapa Roraima, 2000. 5p. (Embrapa Roraima. Comunicado Técnico, 4).

MENON, J.C.M.; BARROS, A.C.S.A.; MELLO, V.D.C.; ZONTA, E.P. Avaliação da qualidade física e fisiológica da semente de soja produzida no Estado do Paraná na safra 1989/90. Revista Brasileira de Sementes, v.15, n.2, p.203208, 1993.

PAULA, M.B.; FILHO, M.B.; CARVALHO, J.G. Arroz de sequeiro. In: RIBEIRO, A.C.; GUIMARÃES, P.T.G.; ALVAREZ, V.H. (Ed.). Recomendações para o uso de corretivos e fertilizantes em Minas Gerais - 5a aproximação.Viçosa, MG, 1999, p.281-284.

PIMENTEL-GOMES, F. Curso de estatística experimental. 12. ed. São Paulo: Nobel, 1987. 467p.
PINHEIRO, B.S.; GUIMARÃES, E.P. Índice de área foliar e produtividade do arroz de sequeiro. 1. Níveis limitantes. Pesquisa Agropecuária Brasileira, v.25, n.6, p.863-872, 1990.

SMIDERLE, O.J.; DIAS, C.T.S. Época de colheita e qualidade fisiológica de sementes de arroz irrigado (Oryza sativa cv. BRS Roraima). Pesquisa Agropecuária Tropical, v.38, n.3, p.188-194, 2008.

SOUZA, L.C.D.; YAMASHITA, O.M.; CARVALHO, M.A.C. Qualidade de sementes de arroz utilizadas no norte de Mato Grosso. Revista Brasileira de Sementes, v.29, n.2, p.223-228, 2007.

TORRES, S. B.; MARCOS FILHO, J. Teste de envelhecimento acelerado em sementes de maxixe (Cucumis anguria L.). Revista Brasileira de Sementes, v.23, n.2, p.108-112, 2001.

VIEIRA, R.D.; CARVALHO, N.M. Testes de vigor em sementes. Jaboticabal: FUNEP, 1994. 164p.

YOSHIDA, S. Fundamental of rice crop science. Los Baños: International Rice Research Institute, 1981, 269p.

ZIMMER, A.H.; MACEDO, M.C.M.; BARCELLOS, A.O.; KICHEL, A.V. Estabelecimento e recuperação de pastagens de Braquiária. In: SIMPÓSIO SOBRE MANEJO DE PASTAGEM, 11., Piracicaba, 1994. Anais... Piracicaba: FEALQ, 1994. p.107-151.

ZONTA, E.P., MACHADO, A.A. Sistema de análise estatística para microcomputadores - SANEST. Registrado na Secretaria Especial de Informática, sob n. 066,060, Categoria A. Pelotas: UFPel, 1984.75p. 